\title{
Effect of Narrow Band -UVB Phototherapy on Circulating T-Regulatory cells and Serum IL-17 Level in Egyptian Patients with Non-Segmental Vitiligo
}

\author{
Magdy Abdel Mageed El Sohafy ${ }^{1}$, Bothaina Mahrous Ghanem ${ }^{1}$, Shereen Salah Mitwally², \\ Ahmed Fathy State ${ }^{1}$, Rasha Abdelgawad Mohammed Elshawaf ${ }^{1}$ \\ Departments of ${ }^{1}$ Dermatology, Andrology \& STDs and ${ }^{2}$ Clinical Pathology, \\ Faculty of Medicine - Mansoura University \\ *Corresponding author: Rasha Abdelgawad Mohammed Elshawaf, Mobile: (+20) 01003694969, \\ E-Mail: dermadrrasha@yahoo.com
}

\section{ABSTRACT}

Background: Vitiligo is an acquired chronic depigmenting disorder of the skin, characterized by the development of milky white macules and patches resulting from a selective loss of epidermal melanocytes. There are various theories about its pathogenesis and the etiology is multifactorial associating genetic and environmental factors together with metabolic and immune alterations.

Objective: To demonstrate the role of circulating T regulatory cells (Treg) (specifically CD4 $4^{+}, \mathrm{CD}^{+} 25^{+}, \mathrm{CD} 4^{+} 25^{+} \mathrm{FoxP} 3$ ) and serum level of IL-17 in pathogenesis of non-segmental vitiligo (NSV) in Egyptian patients.

Patients and methods: This case-control study was carried out on eighty subjects in the period from January 2018 to March 2020, attending Dermatology, Andrology \& STDs Outpatient Clinic of Mansoura University Hospital. Subjects were classified into two groups: Group (1): patients group included forty patients suffering from NSV (vitiligo patients group). Group (2): control group included forty persons who were selected from hospital workers with no personal or family history of vitiligo or systemic autoimmune diseases in their first-degree relatives.

Results: After NBU-VB treatment, there was a highly statistically significant increase in $\mathrm{CD} 4{ }^{+} \%, \mathrm{CD}^{+} 25^{+} \%$ and $\mathrm{CD}^{+} 25^{+} \mathrm{FoxP} 3 \%$ expression with a mean of $12.1 \pm 4$ versus $10 \pm 3.2,3.5 \pm 1.1$ versus $3.2 \pm 1$ and $1.8 \pm 0.6$ versus 1.1 \pm 0.3 when compared to before treatment levels respectively. Also, a highly statistically significant decrease in IL-17 level with the mean of $14.3 \pm 4.1$ versus $19.9 \pm 6 \mathrm{pg} / \mathrm{mL}$ when compared to before treatment levels. There was a highly statistically significant positive correlation between $\mathrm{CD} 4{ }^{+} 25^{+} \%$ expression and $\mathrm{CD} 4^{+} \%$ expression in vitiligo group before and after treatment. Conclusion: Lower $\mathrm{CD}_{4}^{+} \%, \mathrm{CD}^{+} 25+\%$ and $\mathrm{CD}^{+} 25^{+} \mathrm{FoxP} 3 \%$ expression and elevated serum levels of IL-17 positively were correlated with disease severity.

Keywords: Narrow band-UVB phototherapy, T-regulatory cells, Serum IL-17 level, Non-segmental vitiligo.

\section{INTRODUCTION}

Vitiligo is an acquired chronic depigmenting disorder of the skin, characterized by the development of milky white macules and patches resulting from a selective loss of epidermal melanocytes (1). It was recently described as basal melanocyte detachment ${ }^{(2)}$. The exact etiology of vitiligo is unknown. It is frequently associated with multiple autoimmune diseases. There are various theories about its pathogenesis. The etiology is multifactorial, associating genetic and environmental factors together with metabolic and immune alterations. Abnormalities leading to impaired melanocyte regeneration and/or proliferation suggest a primary defect of melanocytes ${ }^{(3)}$. The immune hypothesis is supported by several factors, including the association with autoimmune conditions, organ-specific antibodies, antibodies against antigens in melanocytes and the participation of immune cells ${ }^{(4)}$. The imbalance between melanocytes reactive $\mathrm{CD}^{+}$cytotoxic $\mathrm{T}$ cells and Tregs has been suspected as a potential pathogenesis of vitiligo. Many studies have addressed the role of Tregs in vitiligo ${ }^{(5)}$.

The serum level of TGF- $\beta$ is significantly lower in patients with vitiligo than in controls, suggesting the dysfunction of Tregs in vitiligo. The number of circulating Tregs is lower in patients with vitiligo than in controls ${ }^{(6)}$. Furthermore, the frequency and counts of Treg were significantly decreased in the peripheral blood of active patients than in stable patients. Significant defects in the immunosuppressive function of $\mathrm{CD}^{+}$ $\mathrm{CD} 25^{+}$Tregs in patients with vitiligo on $\mathrm{CD} 4^{+} \mathrm{CD} 25^{-} \mathrm{T}$ cells or $\mathrm{CD}^{+} \mathrm{T}$ cells have been shown by in vitro assays with TCR stimulation ${ }^{(7)}$.

IL-17 is significantly correlated with autoimmune diseases as vitiligo and may be an integral factor in its progression and severity. It has been demonstrated that elevated expression of the proinflammatory cytokine IL-17, either in peripheral blood or in tissues contributes to the pathogenesis of vitiligo ${ }^{(8)}$.

Narrow-band Ultraviolet B (NB-UVB, 310-312 $\mathrm{nm}$ ) is considered the first choice treatment for inducing repigmentation in generalized vitiligo. Its therapeutic effect involves a combination of action in cell cycle kinetics, alterations in cytokine expression, effect on melanocytes and immunomodulation ${ }^{(9)}$. For the treatment of vitiligo, NB-UVB has been shown to be superior to PUVA with respect to rates of repigmentation, particularly for unstable extensive vitiligo, and in achieving more cosmetically acceptable even repigmentation ${ }^{(\mathbf{1 0})}$.

The aim of this study was to demonstrate the role of circulating $\mathrm{T}$ regulatory cells (Treg) (specifically $\mathrm{CD}^{+}, \mathrm{CD}^{+} 25^{+}, \mathrm{CD}^{+} 25^{+}$FoxP3) and serum level of IL17 in peripheral blood of Egyptian patients with nonsegmental vitiligo. 


\section{PATIENTS AND METHODS}

This case-control study was carried out on eighty subjects in the period from January 2018 to March 2020. Subjects were classified into two groups:

Group (1): included forty patients suffering from nonsegmental vitiligo (vitiligo patients group). They were selected randomly from patients attending Dermatology, Andrology \& STDs Outpatient Clinic of Mansoura University Hospital. In all patients, diagnosis of nonsegmental vitiligo depended on clinical examination and was confirmed by woods light.

Group (2): control group included forty persons who were selected from hospital workers with no personal or family history in their first-degree relative of vitiligo or systemic autoimmune diseases. They were apparently healthy persons having age and sex matching with patients group.

\section{Ethical committee and consent:}

The Institutional Review Board (IRB), Faculty of Medicine, Mansoura University approved the whole study design (IRB code: MD/17.03.14). A written informed consent was obtained from each participant before inclusion in the study and after explaining the value of the study. This work has been carried out in accordance with The Code of Ethics of the World Medical Association (Declaration of Helsinki) for studies involving humans.

Inclusion criteria: Patients with non-segmental vitiligo, patients with skin phenotype III or IV, and patients did not receive any topical treatment (for at least one month) or systemic therapy (for at least 3 months) before the study.

Exclusion criteria: Patients with other clinical types of vitiligo, patients with other skin diseases, patients with liver or renal impairment, or history of other systemic disease, patients with history of chronic photodamage, patients with present or past history of skin cancer specially melanoma, and pregnant or lactating females.

\section{All the patients and control were subjected to:}

\section{1-Detailed history taking:}

Personal history: name, age, sex, contact number and address. Present history: onset, course, duration of disease, precipitating factors of vitiligo. Past history of vitiligo, systemic diseases, surgical conditions, previous medication if present and the date of stopping the last treatment modality in patients. Family history of vitiligo. 2- General examination: General examination was done to exclude any signs of any systemic diseases.

3- Dermatological examination: In all patients, diagnosis of non-segmental vitiligo depended on clinical examination, and then was confirmed by woods light. Examination was done to determine the type, distribution and extent of vitiligo lesions. Estimations of VASI score was done before and after 30 sessions of treatment with NB-UVB (narrow band-ultraviolet B) phototherapy for each patients.

\section{4-Narrow band ultraviolet B (NB-UVB) phototherapy:}

Radiation source was Waldmann full-body UV therapy system (UV $100 \mathrm{WL}$ ) with folding side parts, which enable homogeneous irradiation from head to toe, including the lateral body areas. Waldmann UV $100 \mathrm{WL}$ device (Herbert Waldmann, Villingen Schwenningen, Germany) has 8 Phillips TL-01 fluorescent lamps (Eindhoven, Netherlands) with a radiation spectrum of $310-315 \mathrm{~nm}$ and a peak of $311 \mathrm{~nm}$.

\section{5-Laboratory investigation: \\ Blood analysis to assess:}

1. The percentage of Tregs cells in peripheral blood lymphocytes using specific markers: cell surface CD4 and CD25 expression and cytoplasmic FoxP3 expression by using flowcytometry.

2. Serum level of IL-17 using ELISA technique.

\section{Statistical Analysis}

The collected data were revised, coded, tabulated and introduced into a PC using Statistical package for Social Science (IBM Corp. Released 2017. IBM SPSS Statistics for Windows, Version 25.0. Armonk, NY: IBM Corp.). Data were presented and suitable analysis was done according to the type of data obtained for each parameter. Shapiro test was done to test the normality of data distribution. Mean and Standard deviation $( \pm$ SD) for numerical data. Frequency and percentage of non-numerical data. Student t Test was used to assess the statistical significance of the difference between two study group means. For the comparison of more than two groups' means, one way analysis of variance (ANOVA) was used. Chi-Square test was used to examine the relationship between two qualitative variables. The ROC Curve (receiver operating characteristic) provided a useful way to evaluate the sensitivity and specificity for quantitative diagnostic measures that categorize cases into one of two groups. The optimum cut off point is defined as that which maximized the AUC value. The $95 \%$ confidence interval (CI) is used to estimate the precision of the OR. A large $\mathrm{CI}$ indicates a low level of precision of the OR, whereas a small CI indicates a higher precision of the OR. P value $\leq 0.05$ was considered significant.

\section{RESULTS}

Vitiligo patients group included 40 patients. Their mean age was $32.8 \pm 8.3$ years. They included 17 males $(42.5 \%)$ and 23 females (57.5\%). The control group included 40 healthy subjects with mean age of $30.7 \pm 9.5$ years. They included 20 males (50\%) and 20 females (50\%). There were no statistically significant differences between both groups regarding age and gender. Family history of vitiligo was negative of control group and positive in $20 \%$ of cases, with no statistically significant difference between both groups $(p>0.05)$ (Table 1). 
Table (1): Comparison of age, gender and family history of vitiligo between vitiligo patients and control groups

\begin{tabular}{|c|c|c|c|c|c|c|}
\hline \multirow[b]{2}{*}{ Age (years) } & \multirow[b]{2}{*}{ Mean \pm SD } & \multicolumn{2}{|c|}{$\begin{array}{c}\text { Control group } \\
\quad \mathrm{N}=40\end{array}$} & \multicolumn{2}{|c|}{$\begin{array}{l}\text { Vitiligo patients } \\
\text { group } \\
\mathbf{N}=40\end{array}$} & \multirow{2}{*}{$\begin{array}{c}\boldsymbol{P} \\
0.533\end{array}$} \\
\hline & & 30.7 & \pm 9.5 & 32.8 & \pm 8.3 & \\
\hline Males & $\mathrm{N}, \%$ & 20 & $50 \%$ & 17 & $42.5 \%$ & 0.501 \\
\hline Females & $\mathrm{N}, \%$ & 20 & $50 \%$ & 23 & $57.5 \%$ & \\
\hline Positive family history & $\mathrm{N}, \%$ & - & - & 8 & $20 \%$ & 0.210 \\
\hline
\end{tabular}

$\mathrm{N}$, number; $\mathrm{SD}$, standard deviation; $\mathrm{p}$ value is significant $<0.05$.

Table (2): Comparison of CD4+\%, CD4+25+\%, CD4+25+FoxP3\% expression and IL17 levels between vitiligo patients at diagnosis and control groups.

\begin{tabular}{|l|c|c|c|c|c|}
\hline \multirow{2}{*}{} & \multicolumn{2}{|c|}{$\begin{array}{c}\text { Control group } \\
\mathbf{N = 4 0}\end{array}$} & \multicolumn{2}{c|}{ Vitiligo group } & \multirow{2}{*}{ N=40 } \\
\cline { 2 - 5 } & Mean & \pm SD & Mean & \pm SD & \\
\hline $\mathrm{CD}^{+}(\%)$ & 12.4 & \pm 4.1 & 10 & \pm 3.2 & $\mathbf{0 . 0 1 3}$ \\
\hline $\mathrm{CD}^{+}+25^{+}(\%)$ & 4.6 & \pm 1.1 & 3.2 & \pm 1 & $\mathbf{0 . 0 0 7}$ \\
\hline $\mathrm{CD} 4+25^{+} \mathrm{FoxP} 3(\%)$ & 2.5 & \pm 0.7 & 1.1 & \pm 0.3 & $<\mathbf{0 . 0 0 1}$ \\
\hline ILL7 $(\mathrm{pg} / \mathrm{mL})$ & 13.4 & \pm 4.4 & 19.9 & \pm 6 & $<\mathbf{0 . 0 0 1}$ \\
\hline
\end{tabular}

$\mathrm{N}$, number; $\mathrm{SD}$, standard deviation; $\mathrm{p}$ value is significant $<0.05 ; \mathrm{p}$ value is highly significant $<0.001$.

Vitiligo cases showed statistically significantly lower $\mathrm{CD} 4+\%, \mathrm{CD} 4+25+\%, \mathrm{CD} 4+25+\mathrm{FoxP} 3 \%$ expression (mean $\pm \mathrm{SD}=10 \pm 3.2$ versus $12.4 \pm 4.1, \mathrm{p}=0.013 ; 3.2 \pm 1$ versus $4.6 \pm 1.1, \mathrm{p}=0.007 ; 1.1 \pm 0.3$ versus $2.5 \pm 0.7, \mathrm{p}<0.001$ respectively), and statistically significantly higher IL17 level (mean $\pm \mathrm{SD}=19.9 \pm 6$ versus $13.4 \pm 4.4 \mathrm{pg} / \mathrm{mL}, \mathrm{p}<0.001$ ) when compared to control group (Table 2).

Table (3): Comparison of VASI score levels before and after treatment in vitiligo patients' group

\begin{tabular}{|l|c|c|c|c|c|}
\hline & \multicolumn{2}{|c|}{ Before treatment } & \multicolumn{2}{c|}{ After treatment } & \multirow{2}{*}{$P$} \\
\cline { 2 - 5 } & Mean & \pm SD & mean & \pm SD & \multirow{2}{*}{ P.001 } \\
\hline VASI score & 6.7 & \pm 2.2 & 3.4 & \pm 1.1 & $<0.001$ \\
\hline
\end{tabular}

$\mathrm{N}$, number; $\quad \mathrm{SD}$, standard deviation; $\quad \mathrm{p}$ value is significant $<0.05 ; \quad \mathrm{p}$ value is highly significant $<0.001$.

After treatment, vitiligo cases showed a statistically highly significant decrease in VASI score level as compared to before treatment levels $(3.4 \pm 1.1$ versus $6.7 \pm 2.2)$ with $p$ value of $p<0.001$ (Table 3 ).

Table (4): Comparison of $\mathrm{CD}^{+} \%, \mathrm{CD} 4^{+} 25^{+} \%, \mathrm{CD} 4^{+} 25^{+} \mathrm{FoxP} 3 \%$ expression and IL-17 levels before and after treatment in vitiligo patients group.

\begin{tabular}{|l|c|c|c|c|c|}
\hline \multirow{2}{*}{} & \multicolumn{2}{|c|}{ Before treatment } & \multicolumn{2}{|c|}{ After treatment } & \multirow{2}{*}{$\boldsymbol{P}$} \\
\cline { 2 - 5 } & Mean & \pm SD & Mean & \pm SD & \\
\hline $\mathrm{CD}^{+}(\%)$ & 10 & \pm 2.2 & 12.1 & \pm 2 & $<\mathbf{0 . 0 0 1}$ \\
\hline $\mathrm{CD}^{+} 25^{+}(\%)$ & 3.2 & \pm 1 & 3.5 & \pm 0.1 & $<\mathbf{0 . 0 0 1}$ \\
\hline $\mathrm{CD} 4+25^{+} \mathrm{FoxP} 3(\%)$ & 1.1 & \pm 0.3 & 1.8 & \pm 0.6 & $<\mathbf{0 . 0 0 1}$ \\
\hline ILL7 $(\mathrm{pg} / \mathrm{mL})$ & 19.9 & \pm 4 & 14.3 & \pm 3.1 & $<\mathbf{0 . 0 0 1}$ \\
\hline
\end{tabular}

$\mathrm{N}$, number; SD, standard deviation; $\mathrm{p}$ value is significant $<0.05$; $\mathrm{p}$ value is highly significant $<0.001$.

After treatment, vitiligo cases showed a highly statistically significant increase in $\mathrm{CD}^{+} \%, \mathrm{CD}^{+} 25^{+} \%, \mathrm{CD}^{+} 25^{+} \mathrm{FoxP} 3 \%$ expression $(12.1 \pm 4$ versus $10 \pm 3.2, \mathrm{p}<0.001 ; 3.5 \pm 1.1$ versus $3.2 \pm 1, \mathrm{p}<0.001 ; 1.8 \pm 0.6$ versus $1.1 \pm 0.3, \mathrm{p}<0.001$ respectively). Furthermore, there was statistically significant decrease in IL-17 level ( $14.3 \pm 4.1$ versus $19.9 \pm 6 \mathrm{pg} / \mathrm{mL}, \mathrm{p}<0.001)$ when compared to before treatment levels (Table 4).

Table (5): Area under ROC curve and performance criteria of CD4 $\%, \mathrm{CD}^{+} 25^{+} \%, \mathrm{CD}^{+} 25^{+} \mathrm{FoxP} 3 \%$ and IL-17 levels for discrimination between vitiligo patients and control groups.

\begin{tabular}{|c|c|c|c|c|}
\hline & $\mathrm{CD4}^{+} \%$ & $\mathrm{CD}^{+}+25^{+} \%$ & CD4 $+25+$ FoxP3\% & IL17 \\
\hline AUC & 0.659 & 0.721 & 0.962 & 0.780 \\
\hline Cut off & 10.2 & 3 & 1.3 & 16.7 \\
\hline Sensitivity (\%) & 77.5 & 80 & 82.5 & 67.5 \\
\hline Specificity (\%) & 67.5 & 70 & 95 & 77.5 \\
\hline PPV (\%) & 70.5 & 72.7 & 94.3 & 75.0 \\
\hline NPV (\%) & 75.0 & 77.8 & 84.4 & 70.5 \\
\hline Accuracy (\%) & 72.5 & 75.0 & 88.8 & 72.5 \\
\hline$P\left(\right.$ comparison versus $\left.\mathrm{CD4}^{+}\right)$ & - & 0.501 & $<0.001$ & 0.178 \\
\hline$P\left(\right.$ comparison versus $\left.C D 4^{+} 25^{+}\right)$ & - & - & 0.002 & 0.534 \\
\hline$P\left(\right.$ comparison versus $\left.C D 4^{+} 25^{+} F o x P 3\right)$ & - & - & - & 0.001 \\
\hline
\end{tabular}

AUC, area under ROC curve; CI, confidence interval; PPV, positive predictive value; NPV, negative predictive value; $\mathrm{p} 1$, comparison of AUCs of $\mathrm{CD}^{+} \mathrm{CD} 25^{+} \mathrm{FoxP} 3$ and IL17; $\mathrm{p}$ value is significant $<0.05$. $\mathrm{p}$ value is highly significant $<0.001$. 
Receiver operating characteristic (ROC) curve of $\mathrm{CD}^{+}, \mathrm{CD} 4^{+} 25^{+}, \mathrm{CD} 4{ }^{+} \mathrm{CD} 25^{+} \mathrm{FoxP} 3$ and $\mathrm{IL}-17$ was conducted for discrimination between vitiligo patients and control groups. Excellent $\mathrm{AUC}$ was found for $\mathrm{CD} 4{ }^{+} \mathrm{CD} 25^{+} \mathrm{FoxP} 3$ ( $\mathrm{AUC}=0.962$ ). Besides, IL-17 as well as $\mathrm{CD}^{+}+25^{+}$showed fair AUC (AUC $=0.780$ and 0.721 respectively), while $\mathrm{CD}^{+}{ }^{+}$showed poor AUC $(=$ 0.659). At best cut of value of $\mathrm{CD} 4{ }^{+} \mathrm{CD} 25^{+} \mathrm{FoxP} 3=1.3 \%$, sensitivity was $82.5 \%$, specificity was $95 \%$, PPV was $94.3 \%$, NPV was $84.4 \%$ and accuracy was $88.8 \%$. While, at best cut of value of IL-17 $=16.7 \mathrm{pg} / \mathrm{mL}$, sensitivity was $67.5 \%$, specificity was $77.5 \%$, PPV was $75 \%$, NPV was $70.5 \%$ and accuracy was $72.5 \%$. At best cut off value of CD4 $25^{+}=3$, sensitivity was $80 \%$, specificity was $70 \%$, PPV was $72.7 \%$, NPV was $77.8 \%$ and accuracy was $75 \%$. At best cut off value of CD4 ${ }^{+}=10.2$, sensitivity was $77.5 \%$, specificity was $67.5 \%$, PPV was $70.5 \%$, NPV was $75 \%$ and accuracy was $72.5 \%$. AUC of $\mathrm{CD}^{+} \mathrm{CD} 25^{+} \mathrm{FoxP} 3$ was statistically significantly better than AUC of IL-17, CD $4^{+} 25^{+} \%$ and $\mathrm{CD} 4^{+} \%$ for discrimination between vitiligo cases and control subjects $\left(\mathrm{p}=0.001,0.002,<0.001\right.$ respectively). $\mathrm{CD}^{+} 25^{+} \mathrm{FoxP} 3 \%$ was better than $\mathrm{IL}-17, \mathrm{CD}^{+}{ }^{+} 5^{+} \%$ and $\mathrm{CD} 4^{+} \%$ in diagnosis of vitiligo (Table 5).

Table (6): Correlation of $\mathrm{CD} 4 \%$, $\mathrm{CD} 4^{+} 25^{+} \%, \mathrm{CD} 4^{+} 25^{+} \mathrm{FoxP} 3 \%$ expression and IL- 17 with VASI score in vitiligo patients (before and after treatment)

\begin{tabular}{|c|c|c|c|c|c|c|c|c|c|}
\hline & \multicolumn{2}{|c|}{$\mathrm{CD4}^{+} \%$} & \multicolumn{2}{|c|}{$\mathrm{CD4}^{+} \mathbf{2 5}^{+} \%$} & \multicolumn{2}{|c|}{$\mathrm{CD}^{+}{ }^{+} 5^{+} \mathrm{FoxP3} \%$} & \multicolumn{2}{|c|}{ IL17 } \\
\hline & & $r$ & $P$ & $r$ & $p$ & $r$ & $P$ & $r$ & $P$ \\
\hline \multirow{2}{*}{$\begin{array}{l}\text { VASI } \\
\text { score }\end{array}$} & $\begin{array}{l}\text { Before } \\
\text { treatment }\end{array}$ & -0.078 & 0.632 & -0.379 & 0.016 & -0.975 & $<0.001$ & 0.995 & $<0.001$ \\
\hline & $\begin{array}{c}\text { After } \\
\text { treatment }\end{array}$ & -0.022 & 0.894 & -0.378 & 0.015 & -0.995 & $<0.001$ & 0.989 & $<0.001$ \\
\hline
\end{tabular}

$\mathrm{r}$, correlation coefficient; $\mathrm{p}$ value is significant $<0.05 \mathrm{p}$ value is highly significant $<0.001$.

$\mathrm{CD}^{+} 25^{+} \%$ as well as $\mathrm{CD}^{+} 25^{+} \mathrm{FoxP} 3 \%$ expression showed statistically significant negative correlation with VASI score before $(r=-0.379, p=0.016 ; r=-.975, p<0.001$ respectively $)$ and after treatment $(r=-0.378, p=0.015 ; r=-$ $0.995, \mathrm{p}<0.001$ respectively). On the other hand, IL-17 level showed statistically significant positive correlation with VASI score before $(r=0.995, \mathrm{p}<0.001)$ and after treatment $(r=0.989, \mathrm{p}<0.001)$ (Table 6).

Table (7): Correlation of $\mathrm{CD} 4+\%, \mathrm{CD}^{+} 25^{+} \%$ and $\mathrm{CD} 4+25^{+} \mathrm{FoxP} 3 \%$ expression with IL-17 in vitiligo patients' group

\begin{tabular}{|c|c|c|c|c|c|c|c|}
\hline & \multicolumn{2}{|c|}{$\mathrm{CD4}^{+} 25^{+} \%$} & \multicolumn{2}{|c|}{$\mathrm{CD}^{+}{ }^{+} 5^{+} \mathrm{FoxP3} \%$} & \multicolumn{2}{|c|}{ IL17 } \\
\hline & & $r$ & $p$ & $r$ & $P$ & $r$ & $P$ \\
\hline \multirow{3}{*}{ Before treatment } & $\mathrm{CD4}^{+} \%$ & 0.735 & $<0.001$ & 0.114 & 0.485 & -0.035 & 0.832 \\
\hline & $\mathrm{CD4}^{+} \mathbf{2 5}^{+} \%$ & - & - & 0.230 & 0.154 & -0.035 & 0.828 \\
\hline & $\mathrm{CD4}^{+} \mathbf{2 5}^{+}$FoxP3\% & - & - & - & - & -0.964 & $<0.001$ \\
\hline \multirow{3}{*}{ After treatment } & $\mathrm{CD4}^{+} \%$ & 0.577 & $<0.001$ & 0.044 & 0.789 & -0.039 & 0.812 \\
\hline & $\mathrm{CD4}^{+} \mathbf{2 5}+\%$ & - & - & 0.206 & 0.209 & -0.279 & 0.116 \\
\hline & CD4 $^{+} 25^{+}$FoxP3\% & - & - & - & - & -0.515 & $<0.001$ \\
\hline
\end{tabular}

$\mathrm{r}$, correlation coefficient; $\mathrm{p}$ value is significant $<0.05$. $\mathrm{p}$ value is highly significant $<0.001$.

$\mathrm{CD} 4^{+} \mathrm{CD} 25^{+} \%$ expression showed statistically significant positive correlation with $\mathrm{CD} 4 \%$ expression in vitiligo group before $(r=0.735, p<0.001)$ and after treatment $(r=-0.577, p<0.001)$. $C D 4^{+} \mathrm{CD} 25^{+}$FoxP3\% expression showed statistically significant negative correlation with IL-17 in vitiligo group before $(r=-0.964, p<0.001)$ and after treatment $(\mathrm{r}=-0.515, \mathrm{p}<0.001)($ Table 7$)$.

\section{DISCUSSION}

In our study, the mean age of vitiligo patients was $32.8 \pm 8.3$ years. The mean age of the case group was 30.8 years, and 28.11 years in Nejad et al. ${ }^{(11)}$ and Amer et al. ${ }^{(12)}$ studies respectively. However, in Saudi et al. ${ }^{(13)}$ study, mean age of patients was $43.53 \pm 14.35$ years. These data reinforced that vitiligo is a disease that occurs at any age. Also, Silverberg and Silverberg ${ }^{(14)}$ had an opinion regarding the finding of his study that vitiligo was a disease, which can occur at any age.

In our study, the mean age of vitiligo onset was $26.5 \pm 8.3$ years. This is in accordance with the finding of Bhardwaj et al. ${ }^{(15)}$ who reported that the mean age at onset of vitiligo was $20.8 \pm 10.0$ years. On the contrary, Martins et al. ${ }^{\left({ }^{16)}\right.}$ have found that the average age of onset of nonsegmental vitiligo was $6.1 \pm$ 3.1years. Moreover Sinani et al. ${ }^{\left({ }^{17}\right)}$ reported that no significant difference in age of onset of vitiligo between the two sexes.

In our study, we found that the female sex $(57.5 \%)$ was more affected than males $(42.5 \%)$. This is in accordance with the finding of Martins et al. ${ }^{(16)}$ and Saudi et al. ${ }^{(13)}$ who found that the incidence of vitiligo was higher among female sex. This may be attributed to the fact that females are more concerned by the disease and its distressing appearance more than males, leading to an increased and earlier presentation of females to dermatology clinics. In addition, autoimmune diseases are more common among females.

In the present study mean VASI score after NBUVB treatment, vitiligo cases showed a statistically highly significant decrease in VASI score level as compared to before treatment levels $(3.4 \pm 1.1$ versus 
$6.7 \pm 2.2$ ). This is in accordance with the findings of Said et al. (18) who reported that after NB-UVB treatment, vitiligo cases showed a statistically highly significant decrease in VASI score level as compared to before treatment levels $(5.8 \pm 5.7$ versus $8.6 \pm 5.4)$.

In our study, vitiligo cases showed at diagnosis statistically significantly lower $\mathrm{CD} 4^{+} \%, \mathrm{CD} 4^{+} 25^{+} \%$ and $\mathrm{CD} 4{ }^{+} 25^{+} \mathrm{FoxP} 3 \%$ expression when compared to control group $(10 \pm 3.2$ versus $12.4 \pm 4.1,3.2 \pm 1$ versus $4.6 \pm$ 1.1 and $1.1 \pm 0.3$ versus $2.5 \pm 0.7$ respectively). Our results are in agreement with that of Hegab and Attia ${ }^{(19)}$ who showed a statistically significant decrease in the percentage of peripheral $\mathrm{CD}^{+} 25^{+} \mathrm{T}$ cells and FoxP3 Tregs in vitiligo patients compared to healthy controls. Also, our results are matched with several previous studies by Dwivedi et al. ${ }^{(20)}$ and Richetta et al. ${ }^{(21)}$.

In our study, we found a statistically significantly higher IL-17 level (19.9 \pm 6 versus $13.4 \pm$ $4.4 \mathrm{pg} / \mathrm{mL}$ ) when compared to control group. This is in agreement with Zhou et al. ${ }^{(22)}$ who found a significant higher serum IL-17 levels in 45 patients with active nonsegmental vitiligo versus 45 controls using enzymelinked immunosorbent assay $(\mathrm{P}=0.0145)$. Moreover, Aly et al. ${ }^{(23)}$ recorded a significantly higher serum levels of IL-17 among patients with vitiligo (17.48 \pm 8.7 $\mathrm{ng} / \mathrm{ml})$ versus controls $(12.48 \pm 3.33 \mathrm{ng} / \mathrm{ml})(\mathrm{P}=0.001)$.

In the current study, $\mathrm{CD} 4+25^{+} \mathrm{FoxP} 3 \%$ expression showed statistically significant negative correlation with course before treatment $(\mathrm{p}=0.012)$. On the other hand, serum IL-17 level showed statistically significant positive correlation with course before treatment $(\mathrm{p}=0.013)$. Otherwise, $\mathrm{CD} 4^{+} \% \mathrm{CD}^{+} 25^{+} \%$ and $\mathrm{CD}^{+}{ }^{+} 25^{+} \mathrm{FoxP} 3 \%$ expression as well as IL-17 did not show statistically significant correlation with age, onset and duration of disease in vitiligo patients.

In our study, lower $\mathrm{CD}^{+} \mathrm{CD} 25^{+} \mathrm{FoxP} 3 \%$ expression was statistically significantly associated with progressive course when compared to stationary course before treatment with a mean of $0.9 \pm 0.3$ versus $1.3 \pm 0.4, \quad \mathrm{p}=0.030$. While, $\mathrm{CD} 4{ }^{+} \mathrm{CD} 25^{+} \mathrm{FoxP} 3 \%$ expression did not differ significantly according to gender, family history, and clinical types of vitiligo group. Moreover, $\mathrm{CD} 4^{+} \%$ and $\mathrm{CD} 4^{+} 25^{+} \%$ did not differ significantly according to studied parameters in all vitiligo cases. Our result is in agreement with previous studies that detected reduced percentage of $\mathrm{CD}^{+} 25^{+} \mathrm{T}$ cells in peripheral blood of progressive vitiligo patients compared to the patients with stable vitiligo, and functional analysis of peripheral T-regs in vitiligo patients showed a correlation of T-regs functions with the disease status ${ }^{(20,24)}$. Also, another study by Richetta et al. ${ }^{(21)}$ noted that the proportion of peripheral Tregs was lower in patients with progressive vitiligo compared to stable patients. No differences could be observed in the expression of $\mathrm{CD} 25^{+} \mathrm{FOXP} 3^{+}$according to age, gender, or disease duration. Additionally, Hegab and Attia ${ }^{(19)}$ reported that $\mathrm{CD} 4{ }^{+} 25^{+}$Tregs percentage and FoxP3 Tregs percentage did not correlate with patients' age nor vitiligo disease duration.
Higher IL-17 level was statistically significantly associated with progressive course when compared to stationary course before treatment ( $22 \pm$ 7.4 versus $15.9 \pm 5.2, \mathrm{p}=0.020$ ). While, $\mathrm{IL}-17$ level did not differ significantly according to gender, family history, and clinical types of vitiligo. This is in agreement with Tembhre et al. ${ }^{(25)}$ who found that serum level of IL-17A concentrations were significantly increased in active vitiligo compared to stable vitiligo $(\mathrm{P}<0.05)$. They also suggested that altered cellmediated immunity might facilitate the melanocyte cytotoxicity in vitiligo. However, no correlation was found between serum IL-17A level and age, sex, family history, Koebner phenomenon positivity and associated autoimmune diseases in vitiligo cases.

In the present study after NB-UVB treatment, vitiligo cases showed a highly statistically significant increase in $\mathrm{CD}^{+} \%, \mathrm{CD}^{+} 25^{+} \%$ and $\mathrm{CD}^{+} 25^{+} \mathrm{FoxP} 3 \%$ expression with a mean of $12.1 \pm 4$ versus $10 \pm 3.2,3.5$ \pm 1.1 versus $3.2 \pm 1$ and $1.8 \pm 0.6$ versus $1.1 \pm 0.3$ when compared to before treatment levels respectively. In addition, a highly statistically significant decrease was found in IL-17 level when compared to before treatment levels $(14.3 \pm 4.1$ versus $19.9 \pm 6 \mathrm{pg} / \mathrm{mL})$. Our results are in agreement with that of Hegazy et al. (26) who proposed that restoration of the balance between Th17 and Tregs might represent a novel pathway for the improvement that NB-UVB exerts in vitiligo patients. Also, Tembhre et al. ${ }^{(25)}$ detected increased serum levels of IL-10, IL-13, and IL-17A and decreased concentrations of TGF- $\beta 1$ in patients with vitiligo and that might facilitate the melanocyte cytotoxicity. Meanwhile, treatment with NB-UVB was capable of elevating TGF- $\beta$ levels, suggesting that Treg cytokines might play an important role in repigmentation.

In our study, $\mathrm{CD}^{+} 25^{+} \%$ as well as $\mathrm{CD}^{+} 25^{+} \mathrm{FoxP} 3 \%$ expression showed statistically significant negative correlation with VASI score before $(\mathrm{p}=0.016 \& \mathrm{p}<0.001$ respectively) and after treatment $(\mathrm{p}=0.015 \& \mathrm{p}<0.001$ respectively). On the other hand, serum IL-17 level showed a statistically significant positive correlation with VASI score before $(\mathrm{p}<0.001)$ and after treatment $(\mathrm{p}<0.001)$. This result is in agreement with a previous study by Hegazy et al. ${ }^{(26)}$ in which baseline and post-treatment VASI score showed significant positive correlations with lesional IL-17 and IL-22 as well as significant negative correlation with FoxP3 expression. The restoration of Th17/Tregs balance by NB-UVB could be partially responsible for the improvement of vitiligo patients, translated in their study by the significant reduction of their VASI score that went hand in hand with the drop in levels of lesional IL-17 and IL-22 and the rise of FoxP3. This could be attributed to the abolishment of the presumed impact of the disturbed Th17/Tregs balance on vitiligo, which promote its autoimmunity and allow unchecked inflammation and perpetuation of the disease.

\section{CONCLUSION}


Our results suggested that peripheral Treg depletion with impaired immune downregulatory function and elevated serum levels of IL-17 might participate in the autoimmune conditions beyond the pathophysiology and activity of non-segmental vitiligo. Lower CD4 ${ }^{+\%}, \mathrm{CD}^{+} 25^{+\%}, \mathrm{CD}^{+} 25^{+} \mathrm{FoxP} 3 \%$ expression and elevated serum levels of IL-17 positively were correlated with disease severity. $\mathrm{CD} 4^{+} \%, \mathrm{CD}^{+} 25^{+} \%$ and $\mathrm{CD}^{+}{ }^{+} 25^{+} \mathrm{FoxP} 3 \%$ expression was significantly increased after treatment by NB-UVB. IL-17 level was significantly decreased after treatment by NB-UVB.

Financial support and sponsorship: Nil.

\section{Conflict of Interest: Nil.}

\section{REFERENCES}

1. Weiss M (2020): Vitiligo: To Biopsy or Not To Biopsy? Cutis, 105 (4): 189-190.

2. Boukhedouni N, Martins C, Darrigade A et al. (2020): Type-1 cytokines regulate matrix metalloprotease-9 production and E-cadherin disruption to promote melanocyte loss in vitiligo. JCI Insight, 5 (11): 544-558.

3. Abdel-Malek Z, Jordan C, Ho $\mathbf{T}$ et al. (2020): The enigma and challenges of vitiligo pathophysiology and treatment. Pigment Cell \& Melanoma Research, 33 (6): 778-787.

4. Said-Fernandez S, Sanchez-Domínguez C, Salinas-Santander M et al. (2021): Novel immunological and genetic factors associated with vitiligo: A review. Experimental and Therapeutic Medicine, 21 (4): 1-13.

5. Giri P, Dwivedi M, Laddha $\mathbf{N}$ et al. (2020): Altered expression of nuclear factor of activated $\mathrm{T}$ cells, forkhead box $\mathrm{P} 3$, and immune-suppressive genes in regulatory $\mathrm{T}$ cells of generalized vitiligo patients. Pigment Cell \& Melanoma Research, 33 (4): 566-578.

6. Dwivedi M, Laddha N, Arora $P$ et al. (2013): Decreased regulatory $\mathrm{T}$-cells and $\mathrm{CD} 4+/ \mathrm{CD} 8+$ ratio correlate with disease onset and progression in patients with generalized vitiligo. Pigment Cell \& Melanoma Research, 26 (4): 586591.

7. Ujiie H (2019): Regulatory $\mathrm{T}$ cells in autoimmune skin diseases. Experimental Dermatology, 28 (6): 642-646.

8. Metwalli M, Khattab F, El Amin M et al. (2020): The relationship between the levels of interleukin-17 and 25hydroxyvitamin D in vitiligo outcome. Egyptian Journal of Dermatology and Venerology, 40 (1): 1-12.

9. Moftah N, El-Barbary R, Ismail M et al. (2014): Effect of narrow band-ultraviolet $\mathrm{B}$ on $\mathrm{CD} 4+\mathrm{CD} 25$ highFoxP3+Tlymphocytes in the peripheral blood of vitiligo patients. Photodermatology, Photoimmunology \& Photomedicine, 30 (5): 254-261.

10. Ibbotson $S$ (2018): A Perspective on the Use of NB-UVB Phototherapy vs. PUVA Photochemotherapy. Frontiers in Medicine, 5 (2): 184-190.

11. Nejad S, Qadim H, Nazeman L et al. (2013): Frequency of Autoimmune Diseases in Those Suffering from Vitiligo in Comparison with Normal Population. Pakistan Journal of Biological Sciences, 16 (12): 570-574.
12. Amer A, Galal Khater E, Marei A et al. (2019): Evaluation of serum level of 25-hydroxy vitamin d in vitiligo patients. Zagazig University Medical Journal, 25 (6): 935-940.

13. Saudi W, Swelam M, El-Barbary R et al. (2021): Vitamin D receptor (VDR) gene polymorphism in Egyptian vitiligo patients. Journal of Cosmetic Dermatology, 20 (3): 980-986.

14. Silverberg J, Silverberg N (2013): Association Between Vitiligo Extent and Distribution and Quality-of-Life Impairment. JAMA Dermatology, 149 (2): 159-170.

15. Bhardwaj S, Rani S, Kumaran M et al. (2020): Expression of Th17- and Treg-specific transcription factors in vitiligo patients. International Journal of Dermatology, 59 (4): 474-481.

16. Martins C, Hertz A, Luzio P et al. (2020): Clinical and epidemiological characteristics of childhood vitiligo: a study of 701 patients from Brazil. International Journal of Dermatology, 59 (2): 236-244.

17. Sinani A, Roshi E, Lico R (2015): A study on the prevalence and dermatology life quality index on vitiligo in Tirana, Albania. Balkan Military Medical Review, 18 (4): 106-110.

18. Said E, Nagui N, Rashed L et al. (2021): Oxidative stress and the cholinergic system in non-segmental vitiligo: Effect of narrow band ultraviolet b. Photodermatology, Photoimmunology \& Photomedicine, 37 (4): 306-312.

19. Hegab D, Attia M (2015): Decreased Circulating $T$ Regulatory Cells in Egyptian Patients with Nonsegmental Vitiligo: Correlation with Disease Activity. Dermatology Research and Practice, 15: 1-7.

20. Dwivedi M, Helen Kemp E, Laddha $\mathbf{N}$ et al. (2015): Regulatory $\mathrm{T}$ cells in vitiligo: Implications for pathogenesis and therapeutics. Autoimmunity Reviews, 14 (1): 49-56.

21. Richetta A, D'Epiro S, Salvi M et al. (2013): Serum levels of functional T-regs in vitiligo: our experience and mini-review of the literature. European Journal of Dermatology, 23 (2): 154-159.

22. Zhou L, Shi Y, Li K et al. (2015): Increased circulating Th17 cells and elevated serum levels of TGF-beta and IL21 are correlated with human non-segmental vitiligo development. Pigment Cell \& Melanoma Research, 28 (3): 324-329.

23. Aly D, Mohammed F, Sayed K et al. (2017): Is There a Relation between Vitamin D and Interleukin-17 in Vitiligo? A Cross-Sectional Study. Dermatology, 233 (6): 413-418.

24. Ben Ahmed M, Zaraa I, Rekik R et al. (2012): Functional defects of peripheral regulatory $\mathrm{T}$ lymphocytes in patients with progressive vitiligo. Pigment Cell \& Melanoma Research, 25 (1): 99-109.

25. Tembhre M, Sharma V, Sharma A et al. (2013): T helper and regulatory $\mathrm{T}$ cell cytokine profile in active, stable and narrow band ultraviolet $\mathrm{B}$ treated generalized vitiligo. Clinica Chimica Acta., 424 (3): 27-32.

26. Hegazy R, Fawzy M, Gawdat $\mathrm{H}$ et al. (2014): T helper 17 and Tregs: a novel proposed mechanism for NB-UVB in vitiligo. Experimental Dermatology, 23 (4): 283-286. 